\title{
Multiple Intelligences in Classrooms: The Case of Okyeso Primary School in Cape Coast, Ghana
}

\author{
Alex Kwao $^{1} \&$ Yaw Afari Ankomah ${ }^{1}$ \\ ${ }^{1}$ College of Education Studies, University of Cape Coast, Ghana \\ Correspondence: Alex Kwao, College of Education Studies, University of Cape Coast, Ghana.
}

Received: October 10, 2019

Accepted: May 11, 2020

Online Published: May 19, 2020

doi:10.20849/jed.v4i2.745

URL: https://doi.org/10.20849/jed.v4i2.745

\begin{abstract}
The understanding of multiple intelligences in our schools is very paramount. Multiple intelligences unearth diverse inherent talents in children through interactions in the classrooms. The ability to tap these potentialities and capabilities facilitates their career paths and placements. Unfortunately the education system in Ghana precisely our pre- schools appear not to have adequately set up mechanisms to take advantage of multiple intelligences in children. There seems to be cognitively spread approach using one-sided performance appraisal to examine and assess children's intellectual abilities. The paper therefore identifies multiple intelligences strategy as a missing link in classroom interactions. A careful look is to examine the potentialities in children by critical investigation whether there are diverse levels of abilities and processing skills to solve problems. The inquiry was a case study and a mixed method. Primary 3 class was used and sample selection of 20 children and 5 teachers was employed using the purposive technique. Observation and interview were the main instruments. Bar charts and percentage scores were analytical procedures for the quantitative data while the thematic approach was used as concurrent analytical tool for the qualitative data. Verification strategy was by triangulation. Results were so appealing that, both pupils and teachers were able to identify some areas of multiple intelligences in the classrooms. However, these traits and characteristics were exhibited unknowingly. It is recommended that talents in the classrooms should be tapped using holistic approach to assess children's abilities.
\end{abstract}

Keywords: classroom interactions, cognitively spread approach, multiple intelligences

\section{Introduction}

The critical incident about this study is multiple intelligences in the classroom. This inquiry looks at cognitive traits and characteristics among primary school children and how its philosophical underpinnings in multiple intelligences are manifested and translated into diverse talents. The talents place premium on the potentialities in the classroom that can be tapped for future decision making and how it can also call for better placement of children and their bid for self-actualization. Accordingly, these assumptions reflect the new education reforms and standards of Ghana (Ministry of Education \& UKaid, 2018). The standards are designed to codify what a 'good teacher' looks like for Ghana, recognizing the urgent need to improve the quality of the school experience and learning outcomes for all leaners in diverse ways. One major goal which reflects this is sustainable educational development by 2030 is to ensure inclusive and equitable quality education and promote life-long learning opportunities for all (National Teacher Training Council, 2018). The development of the standards is also informed by new international teaching standards whereby teachers are to demonstrate sound content knowledge and pedagogical knowledge. As a reflection to multiple intelligences requires that, teachers' role is complementary to the learning experiences where more facts about pupils need to be discovered, specifically in academic performance or in talented areas. To achieve this, the teacher becomes a catalyst, a guide and a facilitator, thus the driving-force to identify the child's potentialities (Ankomah \& Kwao, 2019). The classroom interaction is to bring about significant changes of what children can do and what processing skills they have acquired to solve problems. The need to trace these potentialities in the classrooms is not only an end in itself but also a means to an end.

This inquiry is an exploratory approach to find out how teachers identify areas where children can make exploits leading to their expansion in capabilities. In this context, the emphasis shows how the methodology in classrooms widens the horizon of thinking among children and whether talents identified equip children in many 
areas. By this the inquiry looks at the interactional display of skills through guided approach of the teacher. Conceptualizing multiple intelligences also requires appropriate and relevant interactions in the classroom and so with the need to find out considerations for evaluation and assessment procedures that reflect the desired goals of pupils' achievement. The necessary tools for value judgments are the accountability checks that are relevant for the creation of children's intellectual profiles. These indeed consider pertinent information about pupils' strengths and proclivities. More so, the study delves into the variations and the way children learn vis-a vis the modes of teaching that determines performance levels as well as talented areas in Ghanaian pre-schools. From observations made, cognitive modes in the classrooms seem to be one-sided and more traditional, thus measure the performance of children scaling outstanding performance to the weaker category only without reference to talented areas. This categorically renders the classrooms more of traditional practice to suggest that multiple intelligences approach is a missing link in the school's curriculum. Accordingly, performance-based assessment and naturally endowed talents have been either narrowed or obliterated. Talent approaches and standards criteria to determine children's level of knowledge, attitudes, skills and problem solving techniques seem not to have the appropriate credentials. The study is considering these omissions as deficit-oriented paradigms in the classrooms. This situation in the inquiry is therefore looking at the methodology of thinking of many kinds of minds and talents in the instructional development of an indigenous Ghanaian classroom in the Central region. The study is guided by two research questions.

\subsection{Research Questions}

1. To what extent do teaching and learning outcomes reflect multiple intelligences?

2. What procedures do teachers adopt to appraise pupils' performance in the classrooms?

\subsection{Significance of the Study}

Multiple intelligence in this context is a holistic approach to identify diverse performance levels in the classrooms.. Therefore the study hopes to unearth policy issues like classroom methodology that reflects of pupils potentialities.

Work serves as reference source for key stakeholders in education such as policy makers, school administrators, teachers, students and parents. That is as a guide to school quality assurance programme and also as curriculum appraisal performance procedure.

The inquiry will come out with the appropriate methods and strategies in the classrooms based on the principles of individual differences and how needs assessment and inherent characteristics of children can be assessed.

The study hopes to come out with the appropriate appraisal performance levels for parents, teachers and students for appropriate decision making on children's progress, career development and, placement.

It will create the platform of awareness creation to students at all levels of their schooling, there by guide them to assess their potentialities in the areas of progress and assessments in their learning experiences.

The study will facilitate guidance and counseling in schools through on the job training for teachers and parents (Ankoma \& Kwao, 2019). By this, teachers and parents will be able to determine potential areas of children from the foundation stages through developmental processes and identifying of talents using the multiple intelligences mode.

\section{Review of Literature}

The literature highlights major issues to include; operationalization of multiple intelligences and empirical issues in the classrooms. Multiple intelligences in a sense is a psychological concept but is integrated with all learning experiences in well defined contexts to describe phenomena. In educational psychology multiple intelligence has its etymology deriving from the word 'intelligence.' This is a tool that measures learning and academic outcomes. It is however described in quantifiable terms as Intelligent Quotient (I Q), the theory which determines the levels of people's ability in learning and how the outcomes are achieved academically (Muijs \& Keynolds, 2011). This notion does not only consider the academically achieved but also areas that transcend attitudinal and psychomotor skills.

Multiple intelligences in contemporary educational context and experiences unearth talents and identifies attributes of the individual (Ankoma and Kwao, 2019). This is to say that multiple intelligences has philosophical description where knowledge becomes an industry of diverse and specialized skills, attitudes and talents. The description of knowledge is placed in a bounded context, thus cognitively but has varied or unique in-herent traits and characteristics that show different abilities, potentialities and talents in individuals. The context though presents pluralized units of talents that constitute primary units of knowledge, it suggests that 
multiple intelligences in individuals has many attributes and not limited in scope and in nature (Ankomah \& Kwao 2019). Exemplification of this can describe a person who is doctor by profession but can also be a footballer and a musician as well. The primary unit may be his profession as a doctor but may also have the skill and potential to perform other tasks. This inter-connection in the cognitive domain is what we contextually describe as multiple intelligences which are required in the classrooms in the development of human capital.

Howard Gardner (1983) was one of the chronicles who propounded multiple intelligences. Gardner proposed a new understanding of the construct of multiple intelligences. According to Gardner, each person has different capabilities and tendencies in different areas and that each individual has several types of intelligences that are intermingled in different ways (Gardner, 1983). Gardner suggested that intelligence has more to do with the capacity for 1. Solving problems, 2. Fashioning products in a context-rich and naturalistic setting. That is the concept intelligence becoming more functional concept that could be seen working in people's lives in variety of ways. The variety of ways is people's inherent capabilities and potentialities. These can manifest in the classrooms, home, public places and institutions.

Gardner classifies multiple intelligences into eight categories. First is the Linguistic category. This has the capacity to use words effectively, whether orally, example as storyteller, orator, or politician. The intelligence includes the ability to manipulate the syntax or structure of language. Others are in language to convince others. Accordingly the linguistic value is used as a tool for communication, problem solving and to show cultural identity. The linguistic category of Gardner provides examples and areas of universal category, thus general contexts. The classroom situation however goes beyond that when it comes to exhibiting of talents. Indeed, these are areas influenced by heredity and environment, innovative methods of teaching and the use of information communication technology.

The second category is the logical mathematical. According to Gardner, it is the capacity to use members effectively (e.g. One can be a mathematician, accountant and also a statistician. This reasoning can extend to one as being a scientist as well as a computer programmer. In such a classroom situation, mathematically inclined children can be endowed with knowledge in engineering, accountancy and medicine. Students with such talents are not limited to this category in which they are placed but can also fit into the linguistic category to reflect the assertion that talents are distributed and not restricted (Ankoma \& Kwao). That is mathematics and science students can have the potential to develop their talents also as language or legal experts. Such traits and characteristics form patterns of behaviours in the classrooms. It also suggests that, learning process by intelligence establishes relationships, functions, classifications, inferences, categorization, generalization and predictions (Gardner, 1985). These are indicators that help the teacher to make wise decisions through observations and assessments as children progress from one stage to another.

The third category in Gardner's assumption is the spatial, thus the ability to perceive the visual-spatial world accurately. For example one becoming a decorator can be an architect and also artist or inventor. The classroom experience is a typical example where some children have interest in drawing shapes and building in a form of visual arts. The spatial aspect shows certain level of talent acquired by children that distinctively make some difference from others. This is a primary skilled area classified under the psychomotor domain.

The fourth category to discuss is bodily kinesthetic. It is the expertise in using one's whole body to express ideas and feelings. It is using one's hands to produce or transform things. Typical example is a craftsperson with multiple skills, thus physical skills, showing co-ordination, dexterity and haptic capacities. Interestingly, the type of intelligence is a combination of the psychomotor skills and affective although there was a blend of the cognitive skills. This in the classroom has all the domains of learning operating simultaneously but with a dominant primary skill. This indeed is the psychomotor skill.

Musical category explains the capacity to perceive and express the understanding of music in a formal way. In the classroom, the formal way may describe the manner in which the learning experience is conducted. The learning experience might have its specific areas of specialization but might as well show specific areas of special skills too. For example, children developing skills as singers or drummers only or acquisition of both skills.

Interpersonal category is the ability to perceive and make distinctions in the moods, intentions, motivations and feelings .This can include sensitivity to facial expressions, voice and gestures. This also has the capacity for discriminating among many different kinds of interpersonal cues and the ability to respond effectively to those cues in some pragmatic ways. It is another aspect of social construction where socialization, voice and specific communication skills merge. Such are the areas of future broadcasters and social commenters. These traits are the roots for eloquent children develop. 
The intrapersonal is about self-knowledge and the ability to act adaptively on the basis of that knowledge. This intelligence includes having an accurate picture of one-self, based on one's own strengths and limitations. These are appraisal skills which show awareness of inner moods, intentions, motivations, temperaments and desires. It also demonstrates the capacity for self-discipline and self-understanding which also serves as observational model of one's self. This is an aspect that raises certain level of self-consciousness which is an intrinsic value. In the classrooms, this principle is the blending of emotions and morality which children exhibit just as some adults do and such areas lead children to be potential counselors, religious leaders and opinion leaders.

According to Gardner, the naturalist view is to show expertise in the recognitions and classifications in numerous species in flora and fauna. This also includes individual's environment, the environmental skills and the capacity to discriminate between living and non-living organisms. This phenomenon in the classroom looks at how good some children appreciate the environment and become great scientists in both social and the natural sciences. This suggests that multiple intelligences can be conceptualized in broader, specific and integrated contexts. In the learning process, it is necessary to identify which of the classifications children belong to and how they can be guided to follow pattern of human development and problem solving mechanisms. This debate therefore allays the doubt that, multiple intelligences are not only pluralistic but can identify specific and multiple talents, traits and behavioural tendencies in children (Ankomah \& Kwao, 2019).

\subsection{Empirical Issues}

In the classroom situation, Harold Bloom (1994) states multiple intelligences are important issues and the actual approaches used depend on the method that teachers employ in order to raise their student's interest and motivations. Harold Bloom theorized teachar-centred approach of the teacher which is a traditional approach that represents theory of teaching. That is, transmission of knowledge based on transferring of information from the teacher to the student, focusing on the content proposed. The content proposed is more or less a lecture method which may expect responses in choral form and not an attempt to identify talents. In the classroom situation assessment is the only yard-stick to assess children which indeed is performance-based. In some cases, the teacher allows contributions from only a fewer children and his or her domination becomes teacher centered. There is therefore the tendency to create undemocratic classrooms where tracing talents become a missing link. Invariably, there is no room to help develop the potentialities of children. Hence this is teaching stereo-typed approach that does not help children to exploit their inherent talents. Under such circumstances talents hence multiple intelligences are limited in scope.

In examining another practical model, Harold Broom (1994) propounded the student-centered theory also called the modern approach, based on active learning. The emphasis is on the learner, the techniques being used is dialogue, problem solving, special skills demonstration and multiple skills in class. Interaction is dominantly shifting of knowledge and skills from the teacher to the student. The teacher in the classroom becomes a catalysts, facilitator and guide to children. The outcome of learning experiences becomes distributive, display of talents and confidence building in children. Also, the learning experience creates a merger of constructivism, phenomenology and greater level of social interactionism. Talents and human resource development widens as classifications of talents spread and every student in class is seen as important in their areas of potentialities. There is also combination of performance-based learning and display of talents which are all manifestations of multiple-intelligences. Comparatively, the learner-centered approach provides more critical thinking in the context of classroom interaction and that make learning more of a holistic approach than the teacher-centered (Ankomah \& Kwao, 2019). Hence, this is a scientific classroom model for the creation of human capital and future placement of students.

The eclectic theories also constitute modern approaches to teaching. It is a mixture of theories that involves the use of modern and traditional technique but the final focus is still the student. The eclectic is also centered on individuality, personality and variety. The rationale behind this literary text is the personalized manner in which students are motivated and convinced that they can be successful in their potential areas. This blend or pedagogical fusion is the combination of teacher-centered, subject-centered and student-centeredness. This carries a pluralist context in identifying talents. This also unearths specific talents but may not necessarily be multiple talents. It is suggested that, student-centered approach identifies talents in diversity since the students inherent talents can lead to other fields of specialty. An example is a mathematician as well as a footballer, and a musician. It is a potentiality from one major domain to others or within a specific domain and special areas within the specifics. Another example is an artist good at graphics, designing and also modeling. The classroom situation then becomes diverse environment where talents can be tapped. Educational attainment and achievement in the curriculum today is to look for areas of multiple intelligences rather than relying on only a general performance of pupils. When this is done, placement and developing talents at the foundation level 
becomes appropriate and relevant to human resource development with exponential effects to achieving meritocracy (Ankoma \& Kwao). The context will therefore require structural changes in the curriculum where the teacher, student, policy makers and other key stakeholders have this realization.

Drawing on scenarios from different backgrounds of children to adulthood, the realization was that: 1. A Ghanaian American technical mogul, named Iddris Sandu became a Rising Star Awardee in the Fale list award. At his early age, he was good at calculations. At the secondary school level, he read history, economics and technical implication. As an adult he was able to develop software for algorithms for companies like Uber, Sharpchat and Instagram. Currently Iddris who doubles as entrepreneur and recognized in the soft ware industry by Mayor Eric and former President Barack Obama of the US is a typical example of this multiple intelligence (Daily Graphic, $12^{\text {th }}$ July, 2019). Talents tapped from the foundation stages suggest that he was good at both science and the social sciences.

In Ghana, a potential footballer known as Asamoah Gyan instinctually developed his career from the foundation stages. At the secondary school, he was good at English, music and dance. At the adult stage, his career earned him up as the best Ghanaian top scholar in Africa (Daily Graphic, $5^{\text {th }}$ June, 2019). As a soccer giant, his primary occupation at both local and the international level, he has also emerged as a musician and a businessman in Ghana. The reality is that his human resource development and growth started from the foundation stages therefore the need for a search of talents in the classrooms is a necessary end.

3. The first female Vice-chancellor of the University of Cape Coast in Ghana, 'Auntie' has a biographical record that, she was very good at English and that continued to the University. At the foundation stages she was also good at mathematics and music. The primary cognitive trait which earned her as one of the brilliant professors in Ghana has also considered her as a good administer. She became a great politician with a ministerial position which indeed describes her identity as integrated personality (Daily Graphic, $10^{\text {th }}$ January, 2012). Relevance of this assertion is that human intelligence is not a one-way affair but rather a multiple dimensional endowed property in individuals (Ankomah \& Kwao, 2019). This in the $21^{\text {st }}$ century is the classroom methodology for the creation of human capital.

4. Four amputees started their elementary school in Accra as children with disabilities. After the elementary school, they took up to vocation, thus as masons. After the training programme, they have become self-employed and now as managers of a construction firm (http/www.ghanaweb.com.ghana-24 ${ }^{\text {th }}$ July, 2019). This social inclusion is another important area where people with disabilities can fit into society by identifying their potentialities, not neglected or discriminated against.

\section{Methodology}

The study adopts constructivism and social interactionism as paradigms to direct analytical procedures. More so, these are means to generate concrete and valid answers to the problem. By constructivism is to find out how content and pedagogical knowledge have been socially constructed in the classrooms and its impact in identifying multiple intelligences among pupils. That is to find out relevance of the student's potentialities in knowledge, industry and creativity (Cohen, Manion \& Morrison, 2008). The use of social interactionism is to assess students' behavioural tendencies through classroom interactions on their ability levels, and skills that they possess as talents. This accounts for evaluation of what pupils can do in the world of their own thinking (Woods, 1979).

The method provides answers to responses regarding multiple intelligences and their implications to inform policy. Research design is typically a mixed approach case study. Primary 3 class was used. Sample selection of 20 pupils and 5 teachers was employed using the purposive technique. Descriptive statistics and interview were the main instruments. Bar charts and percentage scores were analytical procedures for the quantitative data while the thematic approach was used as concurrent analytical tool for the qualitative data. Verification strategy was by triangulation.

\subsection{Discussion}

The biographical data captured 20 pupils' parents. Background information revealed that, there were 11 boys and 9 girls whose parents were; fishermen, teachers, farmers and the unemployed. These were represented in a pie-chart. 


\section{Occupation of Parents}

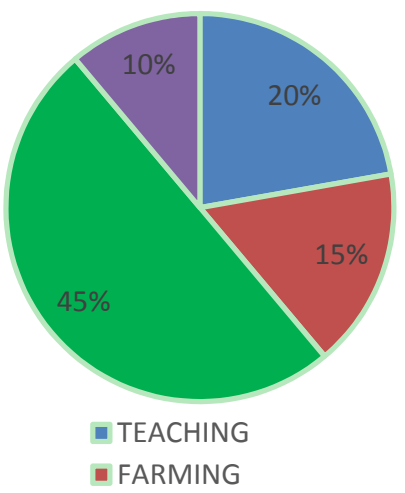

The dominant pre- occupation of the pupils' parents is fishing (45\%). This is followed by teaching (20\%) with the least as unemployed (10\%). The bio-data has the implication that children of the dominant fishermen may not benefit adequately in learning at home since fishing as an occupation is an engagement throughout the day or within the week. Inadequate time for children's learning at home and supervision may not help parents identify potential areas of their children. This identification may only be done by the classroom teacher to suggest that detecting multiple intelligences in children may only be decided by teachers living in such fishing communities. Emergent literacy may therefore be a missing link. Another phenomenon is that parents who are unemployed may not be in better position to address learning needs of their children at home. As dependents, poverty and poor health situations on such parents may retard the development of children's education. It also suggests that children's talented areas under such circumstances lie in the hands of teachers only and not the parental figure in determining the feat of children at home.

From the biographical analysis, it has been discovered that parental social identities, class and status are driving forces that help teachers to make wise decisions on children's progress in education Quote. Inadequate time to facilitate children's learning at home may create learning difficulties and inaccessible avenues for identifying children's potentialities. The background information also revealed that, multiple intelligences can not only be determined by the classroom teacher in spite of the fact that the teacher's role in the classroom is tremendous. The inquiry adduces evidence that the parental figure is necessary in determining multiple intelligences of children.

\subsection{Research One: To What Extent Do Teaching and Learning Outcomes Reflect Multiple Intelligences?}

This analytical procedure was carried out in primary 3 to examine the level of multiple intelligences among children in a dominant fishing community of the Cape Coast Metropolis in Ghana. The fishing community has been captured under the pseudonym 'Wesooloo' which in Ewe language means, 'you are welcome.' Performance of pupils by the class teacher was assessed based on the primary 3 teaching syllabus in subjects indicated in the table. Areas of pupils' multiple intelligences in the classroom were quantified according to aggregate percentage scores.

Table 1. Distribution of aggregate scores by percentage $(\mathrm{N}=20)$

\begin{tabular}{llll}
\hline Subjects & Below Average & Average Marks & Above Average \\
\hline Mathematics & $5(25 \%)$ & $9(45 \%)$ & $6(30 \%)$ \\
\hline English Language & $11(55)$ & $4(20 \%)$ & $5(25 \%)$ \\
\hline Integrated Science & $7(35 \%)$ & $7(35 \%)$ & $6(30 \%)$ \\
\hline Integrated Science & $3(15 \%)$ & $10(50 \%)$ & $7(35 \%)$ \\
\hline RME & $1(5 \%)$ & $4(20 \%)$ & $15(75 \%)$ \\
\hline Physical Education & & $5(25 \%)$ & $15(75 \%)$ \\
\hline Music and Dance & & $4(20 \%)$ & $16(80 \%)$ \\
\hline Creative Arts & $6(30 \%)$ & $14(70 \%)$ \\
\hline
\end{tabular}


The results by aggregate scores showed performance of pupils in Mathematics (45\%) as the average score. More than $75 \%$ of the pupils had a pass mark in Mathematics. Conversely, results from the English language was abysmally performed to suggest that, the use of mother tongue as medium of instruction facilitated teaching and learning in mathematics as compared to the L2, thus English as official language in primary 3. This behavioural tendency may have similar characteristics in the lower primary and perhaps schools in other fishing communities too. Cognitive Academic Language Proficiency (CALP) is therefore seen as effective medium to enhance teaching and learning. By the theoretical and analytical context of the study performance levels in the subjects can be pluralistic view of multiple intelligences since children can excel in most subjects or at least in two subjects. There was also transferability of skills in a particular subject to a specialized area within the same domain. For example, some pupils are good at music and dance, and talented in singing with some others in drumming. Though the primary cognitive reasoning in subject-area performance was music and dance, children's specialized skills at the foundations level were singing and drumming. This identification suggests that such children in the future may be great artists and instrumentalists. The study notes that Gardner's theory of multiple intelligences is contextually placed in a bounded context, thus general concept which limits the scope of understanding. From the inquiry, multiple intelligences can be expressed as a pluralistic assertion and also as a specialized skilled area.

Therefore assessing talents and potentialities in the classrooms does not rest on single single subject but also through multiple or diverse abilities. The best practices in classrooms will require that, human resource development must gear towards identification of talents such that it can be through creativity, innovation and problem solving. This however can be achieved through intrinsic and extrinsic motivation (Ankoma and Kwao, 2019). The concurrent data analysis is based on qualitative interview.

\subsection{Research Question Two: What Procedures Do Teachers Adopt to Appraise Pupils' Performance in the Classroom?}

This aspect of qualitative data is based on the main research question raised above. Themes and data sets were developed using focus group interviews as basis for analyzing data. The participants were five teachers from the Ocheso Primary school. In the discussion the following themes emerged.

\section{Question 1. How do teachers appraise pupils' performance?}

We appraise performance by the use of continuous assessment from homework, classwork, project work and group work, and grade them in every subject, except that at the end of the term there is summative assessment which is the end of term examination. We now have 50\% marks each for both assessments.

The universality of this response implies that assessment at the Primary 3 level is both summative and summative. At the pre-school level. Piaget (1958) assets that continuous assessment must be the only evaluation procedure so as to understand children's behaviours adequately. Continuous assessment also helps to identify their potentialities through academic work and skills development. Therefore more emphasis for using continuous assessment is more appropriate in the Primary 3 class. Such assertions are performance criteria that provide evidence of competent performance of each element Quote. This view also corroborates students' potential for a successful educational experience at schools quote

\section{Question 2. How do you pass value judgment on Pupils' progress?}

We come out with results placing children from $1^{\text {st }}$ position to the last and that is our traditional form of evaluating children's performance.

That is, appraisal looks at the performance of only brighter children which seemed to be bias way of assessing pupils. According to participants, that is the traditional method adopted for the past. Curriculum therefore needs assessment policy.

\section{Question 3.Do you notice any potentialities among pupils?}

Yes, there are a lot of potentialities because some children are good at all the subjects, some in two or more subjects and others having special skills such as playing of football, singing, drumming and dancing, drawing and storytelling.

These attributes have the implications that all children have similar but different talents. It also implies that the class has children who are outstanding pupils, average students with all having diverse talents to support the assertion that multiple intelligences assumes both pluralistic view as well specialized skills (Ankoma and Kwao,2019). As to whether the traditional assessment is still a policy, participants say,

Much as it is traditional, it still remains education policy and nothing is being done as a changed policy. 
There is therefore a missing link between assessment criteria and performance. Even though all talents are required for classroom decision making to inform policy, appraisals to do not show best practices. This suggests limitations in identifying talents and the need for appropriate assessment policies in schools.

Question 4. Are parents aware of their children's performance?

Most of the parents are not aware of these developments since they fail to visit the school to know much about their children's progress.

From the responses most parents seemed to be ignorant about their children's progress in school and so most assessment decisions are directed by the class teacher which is not the best for quality education and quality assurance. The parental figure has less knowledge about the child and determining future growth and human development of the child appeared to be at a disadvantaged end. From the universality of responses, it has also been discovered that, the fishing community has more occupational concerns than educational progress (Ankomah \& Kwao, 2019). This also suggests that heredity and environmental factors have influence on children's education. This indeed is a classical support of criterion development quote

Question 5. Any other comment on inclusive education and gender issues at the community?

All the five teachers affirm that,

There are children with disabilities who don't attend school because parents' perception is that such children have no future.

Social inclusion is absolutely zero and so the potentialities and talents in such children are completely missing. This indeed is another area of ignorance which will rather create increased financial burden and poverty on parents. Such communities are likely to produce large dependency ratio in Ghana. That is, Equal Opportunity Act $(\mathrm{GOG}, 1992)$ is not working.

\section{Question 6. As to gender roles in the community, participants say,}

There are defined roles for boys and girls in the community, some examples are, girls positioning self at the kitchen precisely for cooking and boys left in a relaxed manner at home or sometimes go out for pleasure.

The realization is that the fishing community is highly patriarchal. Accordingly, discrimination against girls at home and perhaps at school may mean marginalization of girls' education against equality and equity (Kwao, 2018). Equal opportunity is therefore a missing link at the fishing community. In developing the human resource, the boys will have comparative advantage in terms of multiple intelligences over the girls because of domesticity as traditional engagement ascribed to girls at home.

\section{What Is New in the Assumptions?}

Referring to the contextual reasoning in the classroom, Gardner's statement is placed in a bounded context, thus presented in a general context. In Ankomah and Kwao's proposition however, multiple intelligences by its conceptual understanding is spread through diverse talents. That is, talents traced from specific traits and characteristics that can be identified in several ways.

According to Ankomah and Kwao talents may emerge strongly in specific domains or by categorization and classifications to suggest that multiple intelligence is distributive and not restricted.

The realization from the indicators of the study described Gardner's view in terms of cognitive grouping in the classroom. Accordingly, the narration showed particular interest areas of children whiles Ankomah and Kwao stressed that ability levels and talents go beyond groupings. That is, children develop into common groupings in classrooms naturally and can also possess specific talents or unique traits and characteristics within the same domain and some in cases different domains. Example is a child good at language and can equally be eloquent in similar language or other languages. From the observations some of children were overall achievers and some so unique in some of the subjects to support the assertion that multiple intelligence is spread.

Another realization was that talented children from diverse traits were more interested in what they can do without much instruction from the teacher. For instance, when it came to music and dance class, some children acted as Master Drummers and Vocalists to an extent that the teacher himself was introduced to some of the cultural values in their community. This indeed was a high sense of intrinsic motivation which needs to be encouraged in the classroom. It also served as an exploratory approach to identify talents in the classroom. The methodology could also promote a form of classroom democracy where children and their peers can share knowledge and also stimulate critical thinking in class.

The revelations in class also promoted free enterprise and that also led to higher degree of creativity among 
children. When allowed to dance the 'Abgaja' music a few disabled children in class joined their colleagues happily to express their interest. This suggests that social inclusion is very important in developing the human resource. The class teacher when interviewed whether that has been normal practice said that was the first time to mean the research work provided a favorable environment to meet such expectations. It also suggests that multiple intelligences has inherent traits and characteristics in children irrespective of their social identities.

The study revealed that, talents in the classrooms can be identified by covert and overt means. The children when motivated can be more resourceful and more creative on their own. On the other hand the teacher applying the methodology of multiple intelligences can be a driving force behind the children's success. Classroom approaches towards the totality of children's personalities therefore require multiple intelligences.

The content and data analysis raised several arguments to agree that, Gardner's theory explored the generality of multiple intelligences as conceptual framework in the classrooms. This indeed is fundamentally categorical. This cognitive assumption suggests that teachers will find it difficult to make critical assessment of pupils' appraisal performance.

From the propositions carried out by Ankomah and Kwao, multiple intelligences in the classrooms could be employed by a way of tracing talented areas of children. In the study, it has been noted that students' talents are integrated, diverse and distributed. These are inextricably interwoven where teachers can easily locate students' potentialities. The two arguments show certain characteristics of complexity in Gardner's assumptions on one hand and simplified version by Ankomah and Kwao on the other hand. This adequately has revealed another form of best practices in the classrooms.

\section{Conclusion}

While recognizing multiple intelligences as appropriate and relevant classroom methodology, the study revealed that, teachers were ignorant and unknowledgeable about this best practice. The reflective mode of investigation identified pluralistic technique in the classroom environment to suggest a stereo-typed methodology and appraisal performance. This was due to the contextualized traditional method which was one-sided cognitive approach based on merit, thus evaluating pupils' performance from the first to the last person. The assessment procedures of pupils indicated some levels of multiple intelligences in some subject areas that reflected Gardner's theory. The universality of teachers' responses adduced further evidence that teachers were not aware of the technique multiple intelligences. Standards and skills by which successful educational experience in the classroom is judged is a missing link. This underpinning is an indication that teachers were not able to use multiple intelligences to unearth talents and potentialities of pupils. The methodology therefore informs policy on the need for best practices in the classroom and harnessing of the human resource potential from the basic to a higher level.

\section{Recommendations}

From the analytical point of view, the following recommendations have been made.

1. The Ministry of Education (MOE) must have a policy to ensure that there are National Teachers' Standards criteria for assessment procedures and child centered learning techniques in the classrooms. This will help identify talents.

2. A policy framework to identify talents in schools must begin from the foundations level to harness the human resource potential towards accelerated development in the country.

3. The teacher is not the only key person to determine multiple intelligences in the classrooms. The parental figure should be a contributing factor to complement efforts of teachers in the classrooms.

4. Educational trends are becoming more complex due to modernization. There is therefore the need for teachers, parents and, Guidance and Counseling Co-ordinators to collaborate and help children identify their appropriate potentialities.

5. There is the need for sensitization programme and awareness creation for parents in fishing communities about quality education for learners. This will to alleviate parity levels in poverty, ignorance and high illiteracy rate which impede growth and development of children's education.

6. Gender and inclusive education are important areas of the schools' curriculum. This must be encouraged in schools and communities since equal opportunity might unearth diverse talents of those at a disadvantaged end. 


\section{References}

Ankomah, K. (2019). Multiple intelligences in classrooms. 20th International Oxford Education Research Symposium, UK.

Bloom, H. (2003). The Sage of Concord. New York: Guardian Unlimited.

Bourgejouje, P., \& Tromp. (2011). Quality Educators: An International study of teacher competences and standards. Education International/Oxfam Novib.

Brophy, J. E., \& Good, T. (1986). Teacher behavior and student achievement. Wittrock. Handbook of research on teaching. New York: Macmillan.

Cohen, L. M., \& Morrison, K. R. B. (2008). Research in Education (6th ed.). London: Routledge Taylor \& Francis Group.

Comenius, J. A. (1957). Selection: Introduction by Jean Piaget. Paris: UNESCO.

Daily Graphic. (2012). A rising star in Ghana. Accra: Graphic Communications Ltd.

Daily Graphic. (2019). A potential footballer and a businessman. Accra: Graphic Communications Ltd.

Daily Graphic. (2019). First female vice-chancellor and a politician. Accra: Graphic Communications Ltd.

Department for Education (UK). (2011). Teachers'Standards Guidance for school leaders, School staff and governing bodies. London: DFE.

Farrant, J. S. (1982). Principles and practice of education. Hong Kong: Longman.

Fletcher, J. (2008). Teacher performance appraisal: What do mathematics lecturers say?. London: Pajoy.

Gardner, H. (1983). Frames of Mind: the theory of multiple intelligences. London: Heinemann.

Gardner, H. (2003). Multiple Intelligences after Twenty years. American Educational Research Association, Chicago, Illinois. $\quad$ Retrieved April 21, 2003, from http://www.pz.harvard.edu/Pls/HG__Ml_after_20_years.pdf

Jordan, R., \& Powell, S. (1995). Skills without understanding. A critique of a Competency Based Model of Teacher Education In Relation To Special Needs. British Journal of Special Education, 22(3), 120-124. https://doi.org/10.1111/j.1467-8578.1995.tb00918.x

Kwao, A. (2018).Traditional practices and girls education in Ghana. The case of the patriarchal system in the Yilo Krobo Municipality. Unpublished PhD thesis.

Ministry of Education (MOE). (2012). Teacher professional development and management at the pre- service level. Accra: MOE.

Mujis, D., \& Reynolds, D. (2011). Effective teaching evidence and practice (3rd ed.). Los Angeles: CA Sage.

National Teacher Training Council. (2018). National teachers' standards for Ghana. Retrieved from www.t-tel.org

Pearson, A. T. (1980). The competency concepts. Educational studies, 11, 145-152. https://doi.org/10.1207/s15326993es1102_3

Pearson, E. S. (1981). Critical thinking appraisal. Pearson assessment. London: Pearson Plc.

Piaget, J. (1983). Piaget's Theory. In P. Mussen (Ed.), Handbook of Child Psychology (4th ed., Vol. 1). New York: Wiley.

Simons, H. (1981). Human problem solving. Englewood Cliffs. H. J: Parent-Hull.

\section{Copyrights}

Copyright for this article is retained by the author(s), with first publication rights granted to the journal.

This is an open-access article distributed under the terms and conditions of the Creative Commons Attribution license (http://creativecommons.org/licenses/by/4.0/). 